\title{
Similar Motor Block Effects and Disposition Kinetics between Lidocaine and ( \pm )Mepivacaine in Patients Undergoing Axillary Brachial Plexus Block during Day Case Surgery
}

Marc A.M. Simon ${ }^{1}$, Tom B. Vree ${ }^{2,}$, Mathieu J.M. Gielen², Leo H.D.J. Booij², and Aart J. Lagerwerf²

${ }^{1}$ Department of Anaesthesiology, Medisch Spectrum Twente, Haaksbergerstraat 55, 7513 ER Enschede, Netherlands, ${ }^{2}$ Institute for Anaesthesiology, Academic Hospital Nijmegen Sint Radboud, Geert Grooteplein Zuid 10, 6525 GA Nijmegen, Netherlands

E-mails: T.Vree@anes.azn.nl; L.Booij@anes.azn.nl; Mat.Gielen@12move.nl; mam.simon@worldonline.nl

Received November 27, 2001; Accepted February 20, 2002; Published May 14, 2002

The aim of this investigation was to compare the clinical effects and pharmacokinetics of lidocaine (one metabolite) and mepivacaine (two metabolites) in 2 groups of 15 patients undergoing axillary brachial plexus anaesthesia. The study had a randomised design. The 30 patients were divided into 2 groups. The patients received either lidocaine $\left(600 \mathrm{mg}=2.561 \mathrm{mMol}+5 \mu \mathrm{g} \mathrm{ml}^{-1}\right.$ adrenaline $)$ or mepivacaine (600 mg $=2.436 \mathrm{mMol}+5 \mu \mathrm{g} \mathrm{ml}^{-1}$ adrenaline), injected via the axilla near the brachial plexus over a period of $30 \mathrm{~s}$. Onset of surgical analgesia was defined as the period from the end of the local anaesthetic injection to the loss of pinprick sensation in the distribution of the ulnar, radial, and median nerve. Motor block was measured. Onset of motor block was similar for both drugs. Lidocaine is eliminated biexponentially with a $t_{1 / 2 \alpha}$ of $9.95 \pm 14.3 \mathrm{~min}$ and $a t_{1 / 2 \beta}$ of $2.86 \pm 1.55 \mathrm{~h}$. Lidocaine is metabolised into MEGX $\left(t_{\max } 2.31 \pm 0.84 \mathrm{~h} ; \mathrm{C}_{\max } 0.32 \pm 0.13 \mathrm{mg} \mathrm{l}^{-1} ; \mathrm{t}_{1 / 2 \beta} 2.36 \pm 2.35 \mathrm{~h}\right.$; total body clearance was $67.9 \pm 28.9 \mathrm{I} \mathrm{h}^{-1}$ ).

Mepivacaine is eliminated rapidly and monoexponentially with a $t_{1 / 2}$ of $4.78 \pm 2.38 \mathrm{~h}$, a $C_{\max }$ of $3.89 \pm 0.83 \mathrm{mg} \mathrm{F}^{-1}$, and a $t_{\max }$ of $0.41 \pm 0.19 \mathrm{~h}$. The total body clearance of mepivacaine is $50 \%$ of that of lidocaine, $26.9 \pm 10.6 \mathrm{I} \mathrm{h}^{-1}$ vs. $67.9 \pm 28.9 \mathrm{I}$ $\mathrm{h}^{-1}$, respectively $(p<0.0001)$. $( \pm)$ Mepivacaine is metabolised into $( \pm) 4-O H m e p i v a c a i n e$ $\left(C_{\max } 0.45 \pm 0.25 \mathrm{mg} \mathrm{l}^{-1} ; t_{1 / 2 \beta} 6.48 \pm 6.57 \mathrm{~h}\right)$ and $( \pm) 2,6$-pipecoloxylidide $\left(C_{\max } 0.56 \pm 0.30\right.$ $\mathrm{mg} \mathrm{l}^{-1} ; \mathrm{t}_{1 / 2 \beta} 1.48 \pm 0.74 \mathrm{~h}$ ).

For the axillary brachial plexus block, lidocaine and mepivacaine show similar pharmacodynamic and pharmacokinetic behaviour, despite the number of metabolites, and can therefore be used to the clinical preference for this regional anaesthetic technique.

KEY WORDS: lidocaine, mepivacaine, regional analgesia, elimination kinetics, disposition

DOMAINS: pharmaceutical sciences, toxicology, metabolism, drug delivery

* Corresponding author. Tel: ++31-24-361 5363; Fax: ++31-24-354 0462.

(C) 2002 with author. 


\section{INTRODUCTION}

For (short-lasting) surgical procedures on the hand and forearm, intravenous regional anaesthesia (IVRA)[1] and axillary brachial plexus block are popular techniques[2,3,4].

With the IVRA technique the local anaesthetic drug is administered intravenously in the bloodless arm, while with the brachial plexus block, the drug is administered into the neurovascular sheath. If surgery demands analgesia of the whole arm, the local anaesthetic must be administered around the brachial plexus in the axilla, or even more proximally. When the drug is administered into the neurovascular sheath, it diffuses into the nerves but also into the adjacent vessels and enters the systemic circulation[4]. After brachial plexus disposition of the local anaesthetic, a pharmacokinetic curve will result, which resembles an oral or intramuscular drug concentration time curve. This means there must be a clear absorption phase.

Good surgical analgesia is achieved with most local anaesthetic agents, but onset and recovery will be different. An applied local anaesthetic technique is safe, provided a suitable local anaesthetic agent is properly used. Lidocaine and mepivacaine are considered to be suitable agents for axillary brachial plexus blockade[3,5,6,7,8,9,10,11]. With day case surgery it is considered to be safe for patients to leave the hospital free of anaesthetic drugs[12,13].

Relatively little has been published on the pharmacokinetics of lidocaine and mepivacaine with their metabolites when used for axillary brachial plexus anaesthesia. Both compounds are eliminated by hydrolysis of the amide bond and by oxidation. Both compounds form a measurable metabolite in plasma, i.e., $( \pm) 4^{\prime}$-hydroxymepivacaine with $( \pm) 2,6$-pipecoloxylidide (PPX) from $( \pm)$ mepivacaine and MEGX (MonoEthylGlycylXylidide) from lidocaine, respectively. The aim of this investigation is to compare the clinical effect and the pharmacokinetics of lidocaine and $( \pm)$ mepivacaine with their metabolites in 2 groups of 15 patients undergoing brachial plexus anaesthesia by axillary disposition.

\section{MATERIALS AND METHODS}

\section{Patients}

The hospital ethics committee of the Medisch Spectrum Twente approved the study, and written consent to participate was obtained from 15 patients scheduled for hand or forearm surgery (Table 1). All patients were classified according to the criteria of the American Society of Anesthesiologists as ASA I or II. Seven men and eight women received mepivacaine. The mean ( \pm s.d.) body weight was $73.5 \pm 13.5 \mathrm{~kg}$, body length was $1.74 \pm 0.06 \mathrm{~m}$, and age was $49.7 \pm 12.3$ years.

Ten men and five women received lidocaine. The mean ( \pm s.d.) body weight was $80.4 \pm 11.7 \mathrm{~kg}$, body length was $1.73 \pm 0.06 \mathrm{~m}$, and age was $55.5 \pm 14.2$ years. The study had a double-blind randomised design.

\section{Patient Preparation}

No premedication was given. Two cannulae were introduced into the arm that was not receiving surgery; one into a suitable vein and the other into the radial artery. The latter was used for continuous monitoring of the arterial blood pressure and for intermittent blood sampling.

Oxygen saturation, pulse rate and EKG, and arterial blood pressure were measured continuously via a Datex "Satlite," (Datex Division of Instrumentarium Corporation, Helsinki, Finland), from the first venous cannulation until withdrawal of the final arterial blood sample.

Axillary block was performed with a Stimuplex 50-mm short-bevel needle connected to the Stimuplex nerve stimulator (B. Braun Melsungen AG, Melsungen, Germany). Using a stimulation mode of $0.5 \mathrm{~mA}, 0.3 \mathrm{~ms}$, and $1.0 \mathrm{~Hz}$, perivascular puncture was performed until muscle contrac- 
TABLE 1

Type of Surgery in Both Groups of Patients

\begin{tabular}{lll}
\hline Patient No. & Lidocaine Surgery & Mepivacaine Surgery \\
\hline 1 & Dupuytren & Tendon suture digit 2 \\
2 & Neurome palm of hand & Dupuytren \\
3 & Arthroplasty saddle joint & Dupuytren \\
4 & Nerve transplantation right arm & Tendon suture digit V \\
5 & Dupuytren & Dupuytren \\
6 & Nerve transplantation left arm & Arthrodese DIP digit III \\
7 & Tenolysis left underarm & Correction ulnaris deviation \\
8 & Synovectomy left wrist dorsal & Carpal tunnel \\
9 & Dupuytren & Arthroscopy right wrist \\
10 & Carpal tunnel & Dupuytren \\
11 & Neurolysis N Medianus left wrist & Dupuytren \\
12 & Dupuytren & Tendon suture digit 2 \\
13 & Distal ulnar resection & Dupuytren \\
14 & Arthrodese DIP digit V & Arthroplasty saddle joint digit 1 \\
15 & Dupuytren & Plastic saddle joint digit 1 \\
\hline
\end{tabular}

tions indicating stimulation of the median nerve were observed. Over a period of about $30 \mathrm{~s}, 40 \mathrm{ml}$ of the local anaesthetic solution were then injected. Concurrently, pressure was applied with the palpating fingers to the neurovascular sheath just distal to the point of entry of the needle.

Completion of local anaesthetic injection was designated $t=0$. Sensory block development was measured by loss of sensation to pinprick in the cutaneous distributions of the sensory nerves innervating the hand, namely the median nerve, the radial nerve, and the ulnar nerve. Sensory block was graded according to Hollmén[9] on a three-point rating scale ( $1=$ absence of cold sensation, $2=$ analgesia, $3=$ anaesthesia). Sensory block testing commenced at $t=0$ and was continued at 2-min intervals for the first $20 \mathrm{~min}$ and at 5-min intervals for the next $20 \mathrm{~min}$. When a sensory block 3 was not achieved within $40 \mathrm{~min}$, additional systemic analgesics were administered or infiltration with $0.5 \%$ bupivacaine in the surgical field was given.

Onset of the surgical analgesia was defined as the period from the end of the injection of the local anaesthetic to a loss of pinprick sensation (a sensory block 3 score) in the distribution of all three nerves.

Motor block was assessed by the Baseline Hydraulic Hand Dynamometer (Fabrication Enterprises, Inc., Irvington, NY). This device measures the squeeze force, i.e., muscle strength, of the hand and forearm in either kilograms or pounds. A normal baseline value was established before commencing the axillary block and designated $100 \%$. The first assessment for motor block was performed 2 min after the end of the local anaesthetic injection $(t=2)$ and then repeated at a 2-min interval for the first $20 \mathrm{~min}$, and at 5-min intervals thereafter in those patients who had not yet achieved a zero value (100\% blockade). The percentage decline in muscle strength from the base line could then be calculated.

\section{Drugs}

Lidocaine (1.5\%) (Xylocaine ${ }^{\circledR},+5 \mu \mathrm{g} \mathrm{r}^{-1}$ adrenaline ) and mepivacaine (1.5\%) (Scandicaine ${ }^{\circledR}$, $+5 \mu \mathrm{g}^{-1}$ adrenaline) were obtained from Astra Pharmaceuticals (Rijswijk, the Netherlands).

Over a period of $30 \mathrm{~s}, 40 \mathrm{ml}$ of the lidocaine solution $\left(40 \times 15 \mathrm{mg} \mathrm{ml}^{-1}=600 \mathrm{mg}=2.561 \mathrm{mMol}\right)$ were injected around the brachial plexus to each of the patients in the lidocaine group. 
Additionally, $40 \mathrm{ml}$ of the mepivacaine solution $\left(40 \times 15 \mathrm{mg} \mathrm{m}^{-1}=600 \mathrm{mg}=2.436 \mathrm{mMol}\right)$ were injected around the brachial plexus over a period of $30 \mathrm{~s}$ to each of the patients in the mepivacaine group.

\section{Side Effects}

Any skin reactions or subjective complaints were noted.

\section{Sampling}

A total of 18 arterial blood samples were taken from each patient. One was drawn immediately before injection $(\mathrm{t}=0)$ and subsequent samples $5,10,15,20,25,30,40,50,60,75,90,105,120$, $135,150,165$, and $180 \mathrm{~min}$. Blood was collected in tubes containing Li-heparin. The samples were centrifuged at $3,000 \mathrm{~g}$, and the plasma separated and stored at $-20^{\circ} \mathrm{C}$ until analysis.

\section{Analysis}

The plasma concentrations of $( \pm)$ mepivacaine $\left(\mathrm{C}_{15} \mathrm{H}_{22} \mathrm{~N}_{2} \mathrm{O}\right.$; CAS number 96-88-8; MW 246.35; $\mathrm{HCl}$ salt CAS number 1722-62-9, MW 282.9) with metabolites ( \pm ) $4^{\prime}$-hydroxymepivacaine $\left(\mathrm{C}_{15} \mathrm{H}_{22} \mathrm{~N}_{2} \mathrm{O}_{2}\right)$ and ( \pm )2,6-pipecoloxyilidide (PPX) were determined by a modified HPLC method as described earlier[14]. Briefly, the method is as follows: Column: Spherisorb 5 ODS, $250 \times 4.6 \mathrm{~mm}$. UV detection was achieved at $210 \mathrm{~nm}$. Mobile phase: $\left(1 \mathrm{~g} \mathrm{H}_{3} \mathrm{PO}_{4}, 0.45 \mathrm{~g}\right.$ TMACl in 11 distilled water)

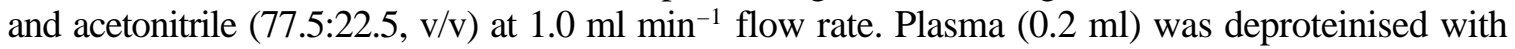
$0.3 \mathrm{ml}$ acetonitrile, vortexed, and centrifuged at $3,000 \mathrm{~g}$. $50 \mathrm{ml}$ was injected onto the column. Retention times were: 4-OHmepivacaine $5.6 \mathrm{~min}$, PPX $9.6 \mathrm{~min}$, mepivacaine $13.2 \mathrm{~min}$. The limit of quantification was $0.30 \mu \mathrm{g} \mathrm{m}^{-1}$ for both compounds. The inter- and intraday coefficients of variance for mepivacaine $\left(0.3-5.0 \mu \mathrm{g} \mathrm{ml}^{-1}\right)$ and both metabolites $\left(0.3-1.0 \mu \mathrm{g} \mathrm{ml}^{-1}\right)$ were less than $5 \%$.

The plasma concentration of lidocaine $\left(\mathrm{C}_{14} \mathrm{H}_{22} \mathrm{~N}_{2} \mathrm{O}\right.$; CAS number 137-58-6; MW 234.33; pKa 7.9; HCL. $\mathrm{H}_{2} \mathrm{O}$ salt CAS number 73-78-9; MW 288.8) and its metabolite MEGX monoethylglycylxylidide $\left(\mathrm{C}_{12} \mathrm{H}_{17} \mathrm{~N}_{2} \mathrm{O}\right.$; MW 220.33) were determined by the same method. The inter- and intraday coefficients of variance for lidocaine and the metabolite were less than $5 \%$.

\section{Pharmacokinetics}

Pharmacokinetic parameters were calculated using a two-compartment model for lidocaine, a onecompartment model for mepivacaine and its two metabolites, and a noncompartimental analysis using the MW/Pharm computer package (Mediware ${ }^{\mathrm{R}}$, Groningen, the Netherlands)[15].

$\mathrm{C}_{\text {max }}$, the maximum plasma concentration $\left(\mathrm{mg} \mathrm{r}^{-1}\right)$ read from the fitted plasma concentrationtime curve $\left(r^{2}>0.98\right)$; $t_{\max }$, the time $(h)$ at which $C_{\max }$ occurred; the elimination half-life associated with the terminal slope of a semilogarithmic concentration-time curve $(\ln 2 / \lambda$, $[\mathrm{h}])$, where $\lambda=$ elimination constant; $\mathrm{AUC}_{\mathrm{t}}, \mathrm{AUC}_{\infty}$, the area under the plasma concentration-time curve $\left(\mathrm{mg} \mathrm{h} \mathrm{l}^{-1}\right)$ calculated (linear trapezoidal method), until the last measured concentration $\left(\mathrm{C}_{\mathrm{t}}\right)$ or extrapolated to $\mathrm{C}_{\mathrm{t}}$ infinity, respectively; $\mathrm{t}_{1 / 2 \text { absorption }}$, the absorption half-life $(\mathrm{h}) ; \mathrm{t}_{1 / 2 \alpha}$, the half-life of the fast elimination phase, and $t_{1 / 2 \beta}$ that of the terminal elimination phase; $\mathrm{CL}_{t}$, body clearance is $\mathrm{F}$. Dose/AUC $\mathrm{t}_{\mathrm{t}}$ (assuming $\mathrm{F}=1$ ).

$\mathrm{CL}$, total body clearance is $\mathrm{F}$. Dose/AUC $\mathrm{A}_{\infty}$, assuming the bioavailability $\left.\mathrm{F}=1\right) ; \mathrm{V}_{\mathrm{d}}=\mathrm{F}$. Dose $/ \mathrm{C}_{0}$, the volume of distribution in the central compartment $(\mathrm{F}=1) ; \mathrm{V}_{\beta}=\mathrm{CL} / \beta$, the volume of distribution in the second compartment. $\mathrm{V}_{\mathrm{ss}}=\mathrm{F}$. Dose . AUMC $\mathrm{AUUC}_{\infty}{ }^{2}$, the volume of distribution at steady state $(\mathrm{F}=1)$. Mean residence time $(\mathrm{MRT})=\mathrm{AUMC}_{\infty} / \mathrm{AUC}_{\infty}$, where $\mathrm{AUMC}_{\infty}$ is the area under the moment curve from zero to infinity. 


\section{Statistical Analysis}

The Mann-Whitney two-tailed test for independent (unpaired) observations was used. Statistical significance was defined as $p<0.05$.

\section{RESULTS}

\section{Clinical Response}

Onset time of sensory block of the median nerve of both drugs was similar. In 27 patients, satisfactory surgical conditions were reached, as evidenced by good sensory blockade. None of the patients showed objective symptoms of toxicity, either local or systemic, during and after injection of the local anaesthetic, nor were there any subjective complaints. Clinically insignificant changes in blood pressure, heart rate and rhythm, or oxygen saturation were observed at any time during the procedure.

Two patients in the lidocaine group failed to develop sensory block in the distribution of the radial nerve within an hour after injection. In both individuals infiltration of the surgical area was necessary with $5 \mathrm{ml}$ bupivacaine $0.5 \%$ (Astra). A third patient in the same group failed to develop any sensory block whatsoever and was given general anaesthesia. The remaining 12 individuals achieved good surgical anaesthesia without additional systemic analgesics.

Decline in muscle power, expressed as percentage of the preanaesthetic baseline, is plotted vs. time in Fig. 1A,B. All patients developed a complete motor block within 20 min of injection. Four patients in the lidocaine group and five patients in the mepivacaine group showed a complete motor block within $2 \mathrm{~min}$, and one patient in each group needed 20 min to reach the 100\% motor block. The remaining patients reached full blockade in varying periods of time as shown in Fig. 1A,B.

The mean lidocaine motorblock-time-effect curve showed two phases, characterised by a $t_{1 / 2 \alpha}$ of $0.098 \mathrm{~min}$ and $\mathrm{t}_{1 / 2 \beta}$ of $4.0 \mathrm{~min}$. Mepivacaine showed a similar effect, and the mean motor blocktime effect curves of lidocaine and mepivacaine were similar $(p=\mathrm{NS})$.

\section{Pharmacokinetics}

\section{Lidocaine}

Figure 2 and Table 2 show the mean plasma concentration-time curves of lidocaine and its metabolite MEGX in 15 patients after axillary administration of the local anaesthetic drug. Lidocaine was quickly absorbed from the tissues $\left(\mathrm{t}_{1 / 2 \mathrm{abs}}=0.14 \pm 0.05 \mathrm{~h}\right)$, resulting in a low $\mathrm{t}_{\max }$ value of $0.43 \pm$ $0.19 \mathrm{~h}$ and $\mathrm{a} \mathrm{C}_{\max }$ of $2.87 \pm 1.19 \mathrm{mg} \mathrm{t}^{1}$. The metabolic formation of MEGX by N-dealkylation started immediately after administration, and the plasma concentration grew in $3 \mathrm{~h}$ to $17 \%$ of that of the parent compound. The elimination of lidocaine is biexponential with a short $t_{1 / 2 \alpha}$ of $9.95 \pm$ $14.3 \mathrm{~min}$ and $\mathrm{at}_{1 / 2 \beta}$ of $2.86 \pm 1.55 \mathrm{~h}$ (Table 3 ).

The formation and elimination of the metabolite MEGX can be described with a one-compartment model. The apparent $\mathrm{t}_{1 / 2 \text { absorption }}$ of MEGC (reflecting its rate of formation minus elimination) is $0.70 \pm 0.43 \mathrm{~h}$, which is five times longer than that of lidocaine $(p<0.0001)$. The $\mathrm{t}_{\max }(2.31 \pm 0.84 \mathrm{~h})$ of MEGX is also five times longer than that of lidocaine $(p<0.0001)$, while its $\mathrm{C}_{\max }$ is lower $(0.32 \pm$ $\left.0.12 \mathrm{mg} \mathrm{l}^{-1}, p<0.0001\right)$. The elimination half life of MEGX is $2.36 \pm 2.35 \mathrm{~h}$ and is similar to that of lidocaine $(p=0.49$, Table 4$)$.

\section{Mepivacaine}

Figure 3 shows the mean plasma concentration-time curves of mepivacaine and its metabolites 4OHmepivacaine and 2,6-pipecoloxylidide (PPX) in 15 patients after axillary administration of the 


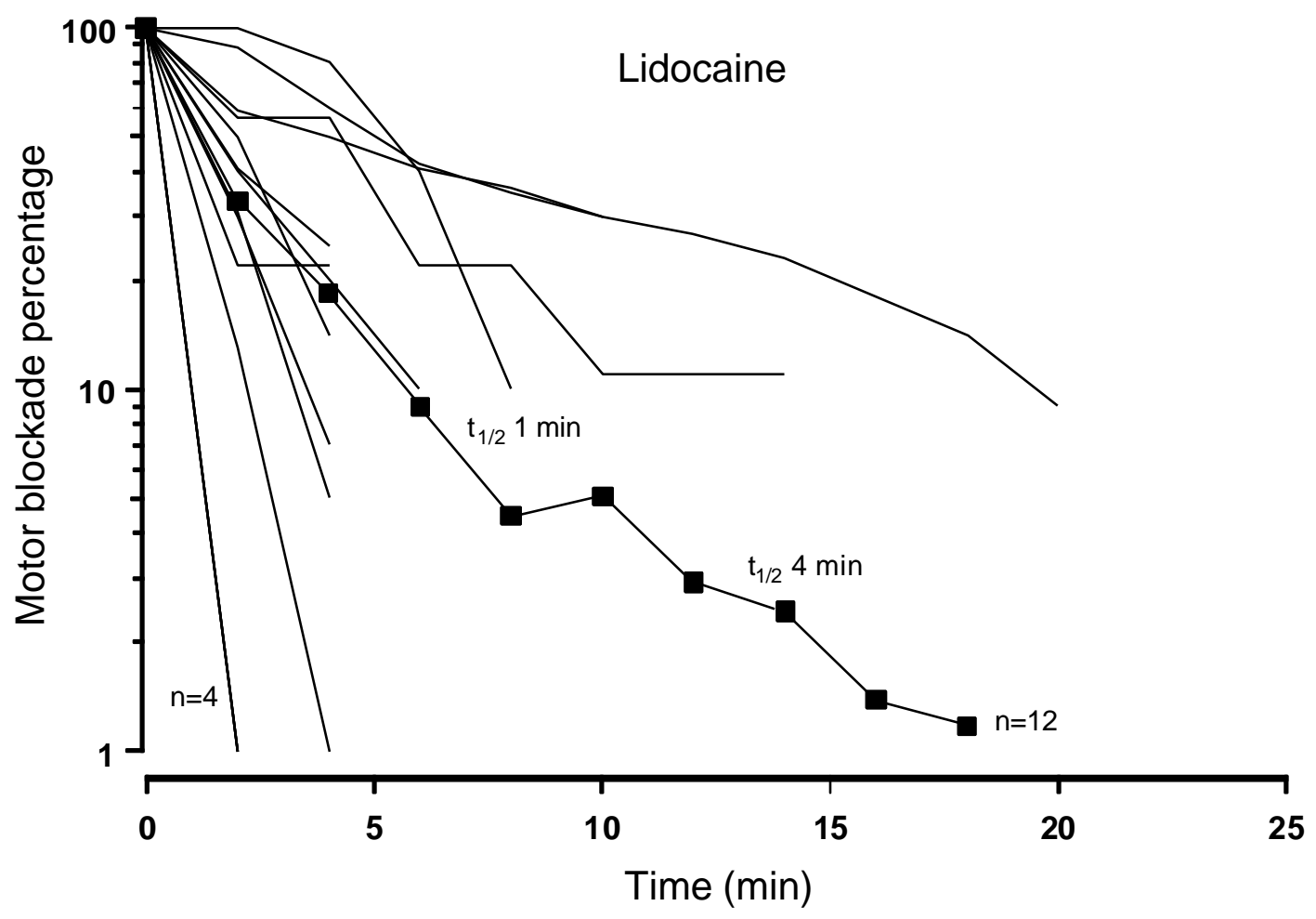

FIGURE 1A

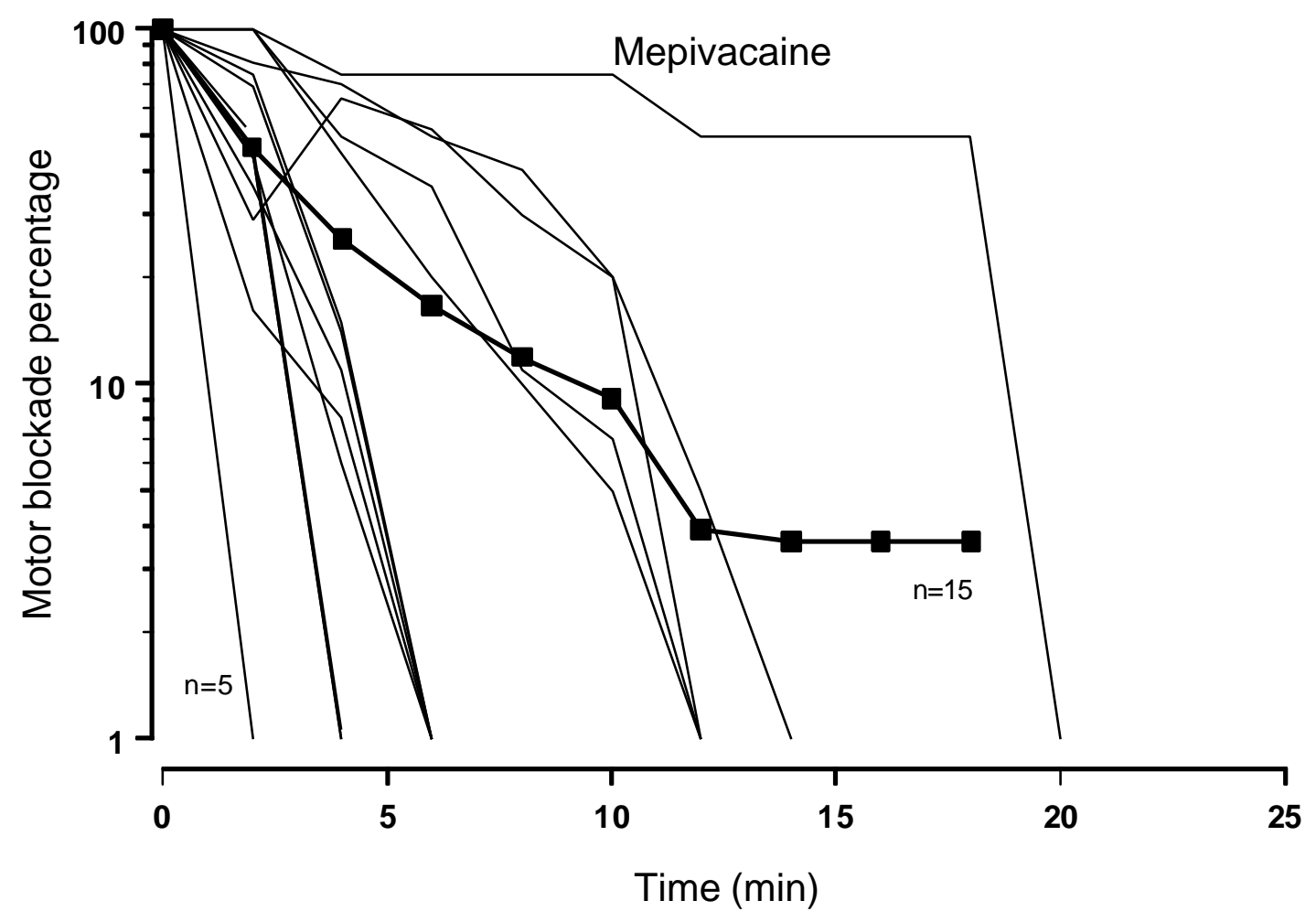

FIGURE 1B

FIGURE 1. (A) Individual and mean $(n=12)$ percentage motorblockade-time curves of lidocaine, after axillary administration of $600 \mathrm{mg}$ lidocaine $\left(+5 \mu \mathrm{g} \mathrm{ml}^{-1}\right.$ adrenaline). Three patients failed to develop a motor block. (B) Individual and mean $(n=15)$ percentage motorblockade-time curves of mepivacaine, after axillary administration of $600 \mathrm{mg}$ mepivacaine $\left(+5 \mu \mathrm{g} \mathrm{ml}^{-1}\right.$ adrenaline). 


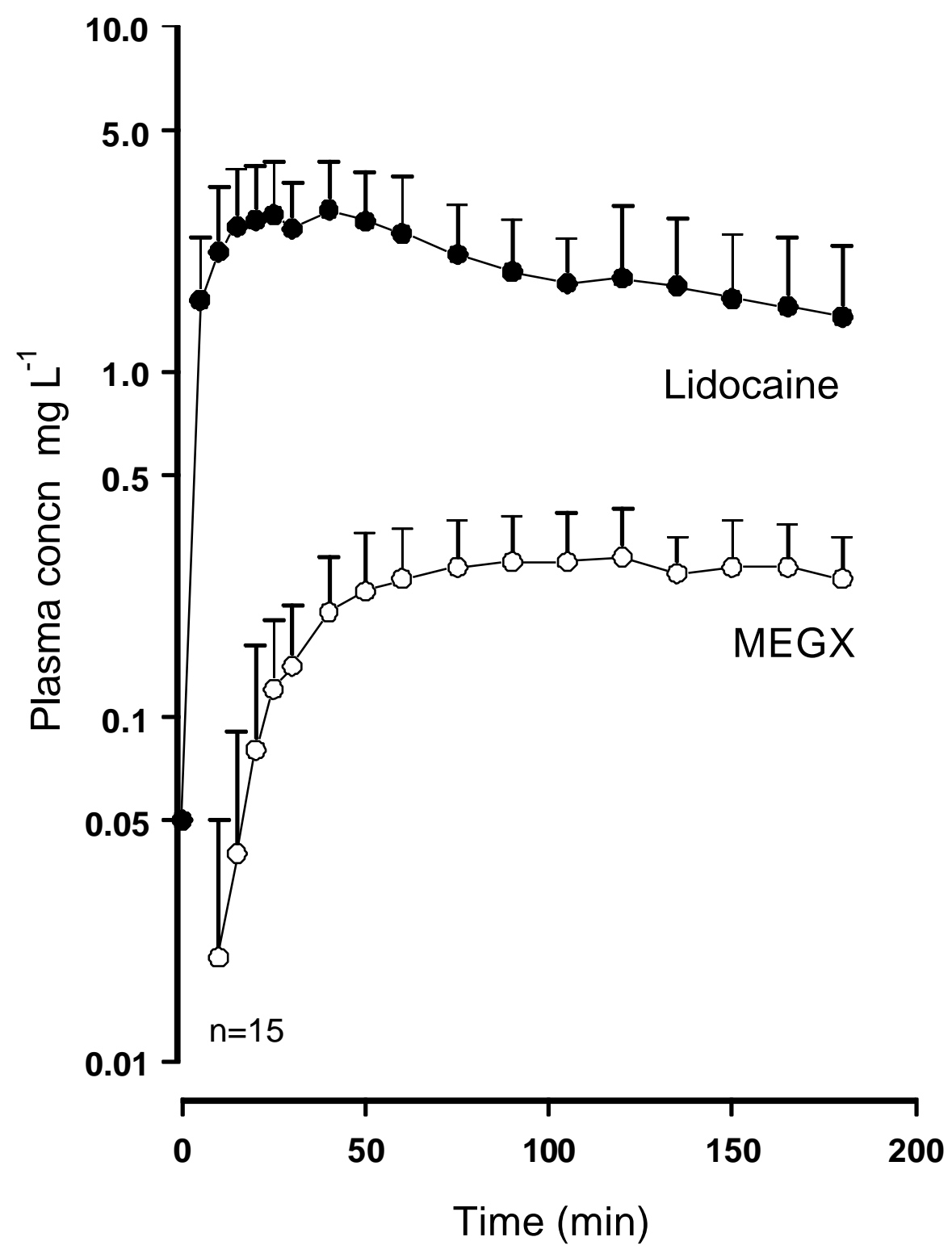

FIGURE 2. Mean plasma concentration-time curves of lidocaine ( $\mathrm{mg}^{-1} \pm$ s.d.), its metabolite MEGX after axillary administration of $600 \mathrm{mg}$ lidocaine $\left(+5 \mu \mathrm{g} \mathrm{ml}^{-1}\right.$ adrenaline $)(\mathrm{n}=15)$.

local anaesthetic drug. Mepivacaine was quickly absorbed from the tissues, resulting in a low $\mathrm{t}_{\max }$ value of $0.41 \pm 0.19 \mathrm{~h}$, which was found almost similar to that of lidocaine $(p=0.32)$, and a $\mathrm{C}_{\max }$ of $3.89 \pm 0.83 \mathrm{mg} \mathrm{t}^{-1}$, which was higher than that of lidocaine $(p=0.0157)$. Mepivacaine is oxidised into 4'-hydroxymepivacaine, and N-dealkylated into 2,6-pipecoloxylidide (PPX). The elimination of mepivacaine is monoexponential, with a $\mathrm{t}_{1 / 2 \mathrm{~b}}$ of $4.78 \pm 2.38 \mathrm{~h}$.

Table 3 shows the mean values ( \pm s.d.) and statistical differences in the pharmacokinetic parameters of lidocaine and mepivacaine. The total body clearance of lidocaine is three times higher than that of mepivacaine, $67.9 \pm 28.91 \mathrm{~h}^{-1}$ vs. $26.9 \pm 10.61 \mathrm{~h}^{-1}$, respectively $(p<0.0008)$. 
TABLE 2

Mean Plasma Concentrations ( $\mathrm{mg} \mathrm{l}^{-1} \pm$ s.d.) of Mepivacaine with Metabolite 4-OH and PPX and Lidocaine with its Metabolite MEGX after Axillary

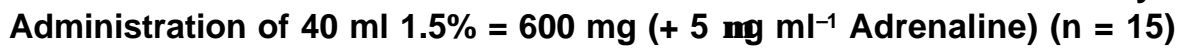

\begin{tabular}{rllllll}
$\begin{array}{c}\text { Time } \\
(\mathbf{m i n})\end{array}$ & Lidocaine & MEGX & \%* & Mepivacaine & 4-OH & PPX \\
\hline 5 & $1.61 \pm 0.82$ & $0.00 \pm 0.01$ & 0 & $2.26 \pm 0.58$ & & \\
10 & $2.22 \pm 1.19$ & $0.02 \pm 0.03$ & 0.9 & $3.26 \pm 0.91$ & & \\
15 & $2.63 \pm 1.22$ & $0.04 \pm 0.05$ & 1.5 & $3.50 \pm 0.77$ & & \\
20 & $2.74 \pm 1.19$ & $0.08 \pm 0.08$ & 2.9 & $3.69 \pm 0.84$ & 0.06 & \\
25 & $2.84 \pm 1.20$ & $0.12 \pm 0.07$ & 4.2 & $3.79 \pm 0.86$ & 0.07 & 0.38 \\
30 & $2.59 \pm 0.92$ & $0.14 \pm 0.07$ & 5.4 & $3.81 \pm 0.97$ & $0.22 \pm 0.19$ & $0.28 \pm 0.10$ \\
40 & $2.94 \pm 1.12$ & $0.20 \pm 0.09$ & 6.8 & $3.75 \pm 0.87$ & $0.32 \pm 0.17$ & $0.33 \pm 0.08$ \\
50 & $2.72 \pm 1.06$ & $0.23 \pm 0.11$ & 8.5 & $4.05 \pm 1.07$ & $0.30 \pm 0.19$ & $0.31 \pm 0.05$ \\
60 & $2.51 \pm 1.17$ & $0.25 \pm 0.10$ & 10.0 & $3.62 \pm 1.02$ & $0.34 \pm 0.18$ & $0.44 \pm 0.10$ \\
75 & $2.18 \pm 0.85$ & $0.27 \pm 0.10$ & 12.4 & $3.37 \pm 1.09$ & $0.39 \pm 0.21$ & $0.53 \pm 0.53$ \\
90 & $1.94 \pm 0.81$ & $0.28 \pm 0.10$ & 14.4 & $3.29 \pm 0.94$ & $0.43 \pm 0.23$ & $0.47 \pm 0.29$ \\
105 & $1.80 \pm 0.62$ & $0.28 \pm 0.11$ & 15.6 & $3.10 \pm 1.03$ & $0.44 \pm 0.24$ & 0.45 \\
120 & $1.86 \pm 1.15$ & $0.29 \pm 0.11$ & 15.6 & $3.15 \pm 1.05$ & $0.51 \pm 0.22$ & $0.52 \pm 0.33$ \\
135 & $1.77 \pm 1.00$ & $0.26 \pm 0.07$ & 14.7 & $2.90 \pm 1.07$ & $0.48 \pm 0.21$ & $0.53 \pm 0.33$ \\
150 & $1.62 \pm 0.87$ & $0.27 \pm 0.10$ & 16.7 & $3.00 \pm 1.18$ & $0.52 \pm 0.24$ & $0.53 \pm 0.33$ \\
165 & $1.54 \pm 0.89$ & $0.27 \pm 0.09$ & 17.5 & $2.70 \pm 1.06$ & $0.45 \pm 0.22$ & $0.47 \pm 0.07$ \\
180 & $1.44 \pm 0.87$ & $0.25 \pm 0.08$ & 17.4 & $2.55 \pm 1.02$ & $0.40 \pm 0.23$ & $0.51 \pm 0.23$ \\
& & & & & \\
\hline
\end{tabular}

* Plasma concentration MEGX/lidocaine x 100\%. Limit of quantitation $0.02 \mu \mathrm{g} \mathrm{ml}^{-1}$.

** Plasma concentration metabolite/mepivacaine $\times 100 \%$.

TABLE 3

Comparison of the Pharmacokinetic Parameters (Mean \pm s.d.) of Lidocaine and Mepivacaine after Axillary Administration of $40 \mathrm{ml} \mathrm{1.5 \% =600} \mathrm{mg} \mathrm{(+5} \mu \mathrm{g} \mathrm{ml}^{-1}$ Adrenaline) in 15 Patients

\begin{tabular}{|c|c|c|c|c|}
\hline \multicolumn{2}{|c|}{ Parameter } & \multirow{2}{*}{$\begin{array}{l}\text { Lidocaine } \\
10 / 5\end{array}$} & \multirow{2}{*}{$\begin{array}{l}\text { Mepivacaine } \\
7 / 8\end{array}$} & \multirow[t]{2}{*}{$p$} \\
\hline Subjects & $\mathrm{M} / \mathrm{F}$ & & & \\
\hline Body weight & $\mathrm{kg}$ & $80.4 \pm 11.7$ & $72.8 \pm 13.9$ & 0.12 \\
\hline Age & Years & $55.5 \pm 14.2$ & $49.7 \pm 12.3$ & 0.24 \\
\hline Length & $\mathrm{cm}$ & $173.5 \pm 64.2$ & $172.5 \pm 7.6$ & 0.70 \\
\hline \multirow[t]{2}{*}{ Dose } & $\mathrm{mg}$ & 600 & 600 & \\
\hline & $\mathrm{mMol}$ & 2.561 & 2.436 & \\
\hline $\mathrm{AUC}_{\infty}$ & $\mathrm{mg} \mathrm{h} \mathrm{I}^{-1}$ & $10.5 \pm 5.24$ & $30.4 \pm 22.6$ & 0.0008 \\
\hline $\mathrm{AUC}_{3 \mathrm{~h}}$ & $\mathrm{mg} \mathrm{h} \mathrm{I}^{-1}$ & $5.48 \pm 1.71$ & $9.51 \pm 2.59$ & 0.0016 \\
\hline $\mathrm{Cl}_{\infty}$ & $\mathrm{Ih}^{-1}$ & $67.9 \pm 28.9$ & $26.9 \pm 10.6$ & 0.0008 \\
\hline $\mathrm{Cl}_{3 \mathrm{~h}}$ & $I h^{-1}$ & $120 \pm 39.8$ & $66.6 \pm 14.4$ & 0.0016 \\
\hline $\mathrm{V}_{\mathrm{d}}$ & I & $92.2 \pm 61.2$ & & \\
\hline$V_{s s}$ & I & 229. \pm 70.6 & & \\
\hline$V_{B}$ & I & $241 . \pm 75.9$ & $150.4 \pm 27.12$ & 0.0071 \\
\hline$t_{1 / 2 a b s o r p t i o n}$ & $\mathrm{~h}$ & $0.14 \pm 0.05$ & $0.064 \pm 0.035$ & 0.0022 \\
\hline$t_{1 / 2 \alpha}$ & $\min$ & $9.95 \pm 14.3$ & & \\
\hline$t_{1 / 2 \beta}$ & $\mathrm{h}$ & $2.86 \pm 1.55$ & $4.78 \pm 2.38$ & 0.0106 \\
\hline MRT & $\mathrm{h}$ & $4.02 \pm 1.79$ & $7.00 \pm 3.45$ & 0.0087 \\
\hline$t_{\max }$ & $\mathrm{h}$ & $0.43 \pm 0.19$ & $0.41 \pm 0.19$ & 0.3225 \\
\hline $\mathrm{C}_{\max }$ & $\mathrm{mgl}^{-1}$ & $2.87 \pm 1.19$ & $3.89 \pm 0.83$ & 0.0157 \\
\hline
\end{tabular}

$\mathrm{p}=$ Mann-Whitney two-tailed test. 
TABLE 4

Comparison of the Pharmacokinetic Parameters (Mean \pm s.d.) of the Lidocaine and Mepivacaine Metabolites MEGX, 4-OH, and PPX after Axillary Administration of $40 \mathrm{ml} \mathrm{1.5 \% =600} \mathrm{mg} \mathrm{(+5} \mathrm{mg} \mathrm{ml-1} \mathrm{Adrenaline)} \mathrm{in} 15$ Patients

\begin{tabular}{|c|c|c|c|c|c|c|c|}
\hline \multicolumn{2}{|c|}{ Parameter } & \multirow{2}{*}{$\begin{array}{l}\begin{array}{l}\text { Lidocaine } \\
\text { MEGX }\end{array} \\
10 / 5\end{array}$} & \multirow[t]{2}{*}{$p$} & \multirow{2}{*}{$\begin{array}{l}\text { Mepivacaine } \\
P P X\end{array}$} & \multirow[t]{2}{*}{$p$} & \multirow[t]{2}{*}{$4-\mathrm{OH}$} & \multirow[t]{2}{*}{$p^{*}$} \\
\hline Subjects & $\mathrm{M} / \mathrm{F}$ & & & & & & \\
\hline Body weight & $\mathrm{kg}$ & $80.4 \pm 11.7$ & & $72.8 \pm 13.9$ & 0.12 & & \\
\hline Age & Years & $55.5 \pm 14.2$ & & $49.7 \pm 12.3$ & 0.24 & & \\
\hline Length & $\mathrm{cm}$ & $173.5 \pm 64.2$ & & $172.5 \pm 7.6$ & 0.70 & & \\
\hline \multirow[t]{2}{*}{ Dose } & $\mathrm{mg}$ & 600 & & 600 & & & \\
\hline & $\mathrm{mMol}$ & 2.561 & & 2.436 & & & \\
\hline $\mathrm{AUC}_{¥}$ & $\mathrm{mg} \mathrm{ht^{-1 }}$ & $2.22 \pm 1.10$ & 0.22 & $67.1 \pm 88.6$ & 0.045 & $4.25 \pm 2.56$ & 0.73 \\
\hline $\mathrm{AUC}_{3 \mathrm{~h}}$ & $\mathrm{mg} \mathrm{h} \mathrm{t}^{-1}$ & $0.67 \pm 0.24$ & 0.22 & $1.11 \pm 0.51$ & 0.045 & $1.05 \pm 0.052$ & 0.74 \\
\hline \% AUCparent & & 13.0 & & 3.89 & & 3.24 & \\
\hline $\mathrm{t}_{1 / 2 \mathrm{absorption}}$ & $\mathrm{h}$ & $0.70 \pm 0.43$ & 0.17 & $1.20 \pm 0.87$ & 0.79 & $0.79 \pm 0.75$ & 0.30 \\
\hline$t_{1 / 2 B}$ & $\mathrm{~h}$ & $2.36 \pm 2.35$ & 0.73 & $1.48 \pm 0.74$ & 0.0628 & $6.48 \pm 6.57$ & 0.087 \\
\hline MRT & $\mathrm{h}$ & $5.32 \pm 3.22$ & $>0.8$ & $4.90 \pm 0.17$ & 0.12 & $10.7 \pm 8.90$ & 0.29 \\
\hline$t_{\max }$ & $\mathrm{h}$ & $2.31 \pm 0.84$ & 0.0171 & $3.19 \pm 0.28$ & 0.16 & $1.86 \pm 0.50$ & 0.0052 \\
\hline $\mathrm{C}_{\max }$ & $m g t^{-1}$ & $0.32 \pm 0.12$ & 0.0219 & $0.56 \pm 0.30$ & 0.18 & $0.45 \pm 0.25$ & 0.32 \\
\hline
\end{tabular}

$\mathrm{p}=$ Mann-Whitney two-tailed test, between MEGX and 4-OH and PPX.

$\mathrm{p}^{*}=$ Mann-Whitney two-tailed test, between 4-OH and PPX.

$\% A U C p a r e n t=A U C m e t a b o l i t e\left(\mathrm{mMol} \mathrm{h}^{-1} ; 3 \mathrm{~h}\right) / \mathrm{AUC}$ parent $\left(\mathrm{mMol} \mathrm{h}^{-1} ; 3 \mathrm{~h}\right)$

The volume of distribution $\left(\mathrm{V}_{\mathrm{b}}\right)$ of mepivacaine is smaller than that of lidocaine $(p=0.0071)$, its $\mathrm{C}_{\max }$ value is higher, $3.89 \pm 0.83$ vs. $2.87 \pm 1.19 \mathrm{mg} \mathrm{l}^{-1}$, resp $(p=0.0157)$.

Table 4 shows the pharmacokinetic parameters of the metabolites. The $\mathrm{t}_{\max }$ and $\mathrm{C}_{\max }$ of the two xylidide metabolites differed significantly; with PPX the $\mathrm{C}_{\max }$ occurs later, and it is higher than the $\mathrm{C}_{\max }$ of MEGX.

\section{DISCUSSION}

For axillary brachial plexus block a rapid onset of good surgical anaesthesia seems to be important, but above all the local anaesthetic agent should be safe. ( \pm )Mepivacaine and lidocaine both fulfill these criteria as reported by several authors[5,7,11,16,17,18]. Eriksson reported that with lidocaine (450 mg without adrenaline) 6 out of 20 patients showed signs of CNS toxicity about 10-15 min after axillary administration, i.e., pronounced dizziness and nearly a loss of consciousness in one patient. Reported onset time for lidocaine was $26.6 \pm 4.1 \mathrm{~min}$.[18]. We added adrenaline to slow absorption and to reduce systemic side effects.

The onset of motor block by lidocaine and mepivacaine with $5 \mu \mathrm{g} \mathrm{ml}^{-1}$ adrenaline was similar. Development of motor blockade in the present study showed a wide range of rates and proceeds apparently independently of the plasma concentration time curve (Fig. 1 A,B and Fig. 4). The endpoint of $100 \%$ motor blockade was achieved within 2 min by four patients in the lidocaine group and by five patients in the mepivacaine group, while in each group one patient needed a full 20 min. Meanwhile, the local anaesthetic is absorbed and appears in the general circulation.

The absorption of both lidocaine and mepivacaine from the axilla region was relatively fast $\left(\mathrm{t}_{\max }\right.$ $0.43 \mathrm{~h}$, respectively $0.41 \mathrm{~h}$ ). The maximum plasma concentrations of both lidocaine and mepivacaine were in agreement with those reported earlier[18,19,20,21,22,23] and stayed well below the toxic concentrations of 5-10 $\mathrm{g} \mathrm{m} \mathrm{m}^{-1}[24,25,26]$. Thereafter, lidocaine was eliminated according a 


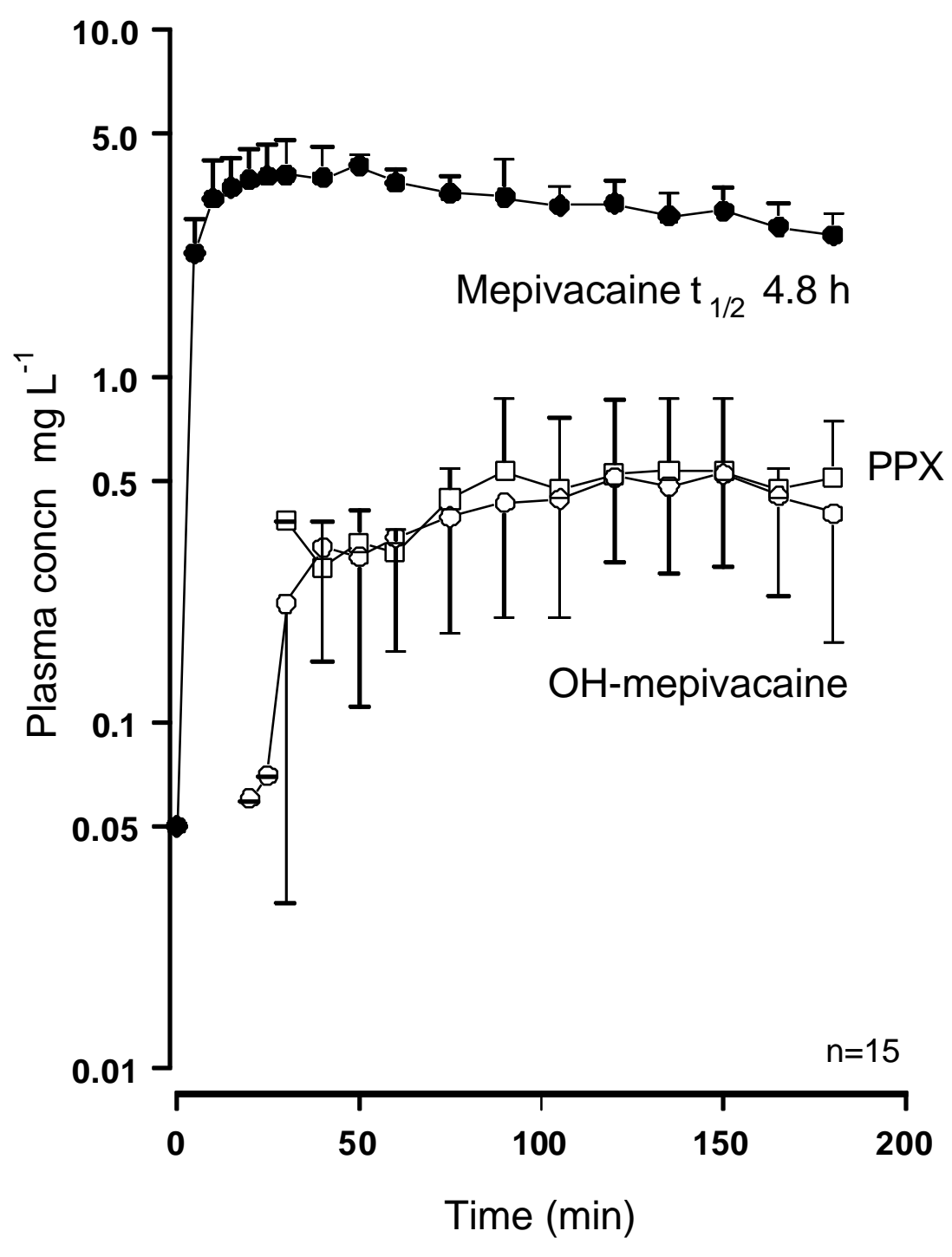

FIGURE 3. Mean plasma concentration-time curves of mepivacaine ( $\mathrm{mg} \mathrm{t}^{1} \pm$ s.d.), and its metabolites $4^{\prime}-$ hydroxymepivacaine (4-OH, open dots) and 2,6-pipecoloxylidide (PPX, open squares) after axillary administration of $600 \mathrm{mg}$ mepivacaine $\left(+5 \mathrm{mg} \mathrm{ml}^{-1}\right.$ adrenaline) $(\mathrm{n}=15)$.

biexponential decay with $t_{1 / 2 \alpha}$ of $9.95 \pm 14.3$ min and a $t_{1 / 2 \beta}$ of $2.86 \pm 1.55$ h. Mepivacaine was eliminated according to a monexponential decay with a $\mathrm{t}_{1 / 2 \beta}$ of $4.78 \pm 2.38 \mathrm{~h}$, which differed from that of lidocaine $(p=0.0106)$. The pharmacokinetic data shown in Table 3 correspond with those previously reported[6,7,10,11].

The large $\% \mathrm{CV}$ in the $\mathrm{t}_{1 / 2 \alpha}$ of lidocaine was caused by some exceptionally long $\mathrm{t}_{1 / 2 \alpha}$ values. In the lidocaine group 6 out of 15 patients showed a long $\mathrm{t}_{1 / 2 \alpha}$ of $23.9 \pm 13.5 \mathrm{~min}$, which differed from the short values of $0.63 \pm 0.71 \mathrm{~min}(p=0.0018)$. Three patients did not develop a sensory block in all nerves after lidocaine injection; this may be due to poor distribution over the nerves. However, this lack of sensory block could not be related to the individual plasma concentration-time curves and pharmacokinetics. The differences in the mepivacaine group were much smaller. 


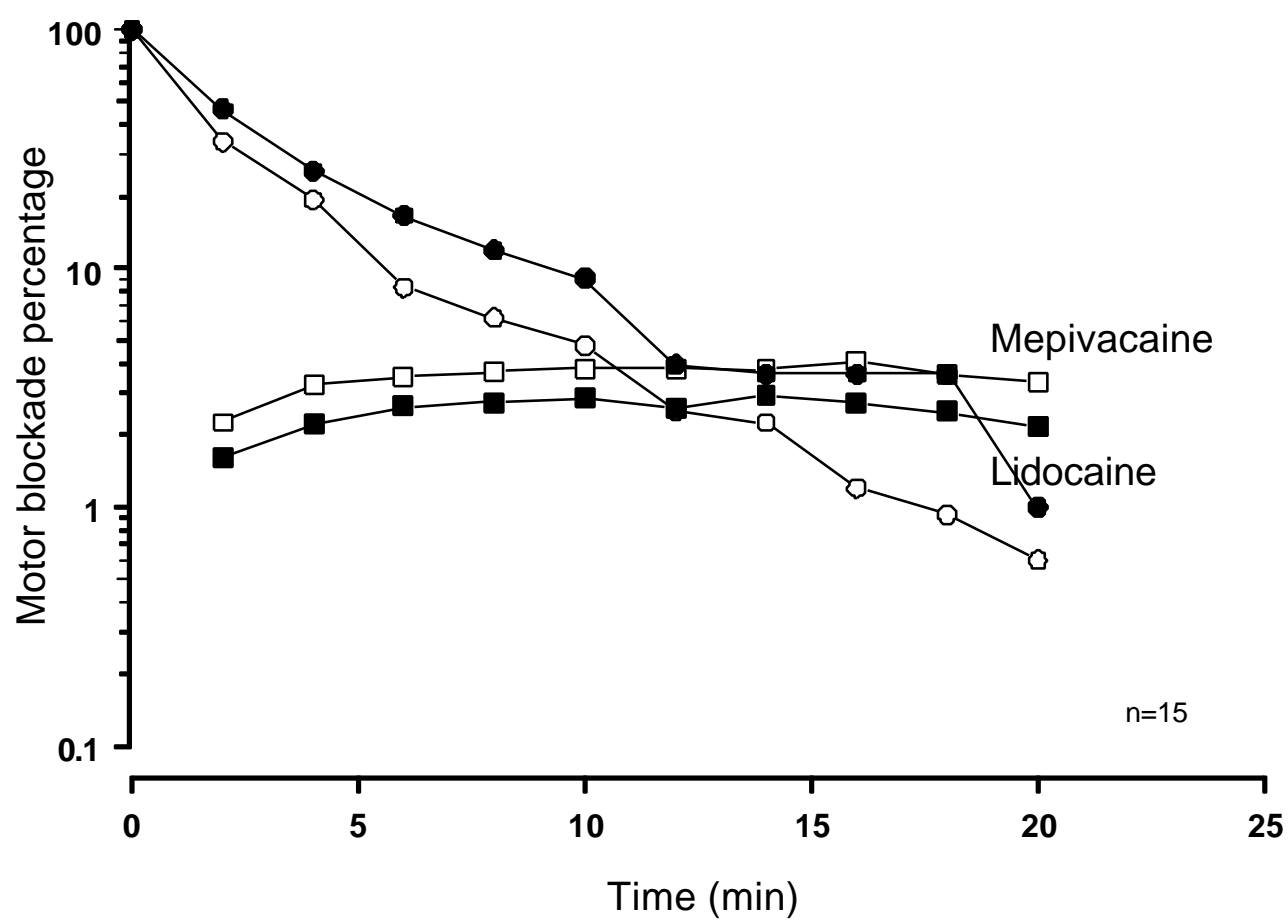

FIGURE 4. Mean percentage motor blockade (dots) and mean plasma concentration-time curves (squares) of lidocaine (solid symbols), and mepivacaine (open symbols) after axillary administration of $600 \mathrm{mg}\left(+5 \mu \mathrm{g} \mathrm{ml}^{-1}\right.$ adrenaline) $(\mathrm{n}=15)$. Decrease in motor blockade can be tested only before surgery, while testing of the recovery is not possible due to appendages.

\section{$\mathrm{AUC}_{\infty}$ vs. $\mathrm{AUC}_{3 \mathrm{~h}}$}

The difference between the pharmacokinetics of lidocaine and mepivacaine can be attributed solely to the difference in $\mathrm{C}_{\max }$ and $\mathrm{t}_{1 / 2}$ values, which affects the $\mathrm{AUC} \infty$, and $\mathrm{AUC}_{\mathrm{t}}$ and thus the calculated total body clearance. Clearance values were based on $\mathrm{CL}=\mathrm{F}$.Dose/AUC $\mathrm{An}_{3 \mathrm{~h}}$ with the assumption that $\mathrm{F}=1$. The clearance values of the metabolite (MEGX, PPX, 4-OH) must be multiplied by the fraction of the dose that is converted into metabolite. The plasma concentration of both parent compounds did not reach the limit of quantification at $\mathrm{t}=3 \mathrm{~h}$, which makes the difference between the extrapolated $\mathrm{AUC}_{\infty}$ and $\mathrm{AUC}_{3 \mathrm{~h}}$ constant. $\mathrm{The}_{\mathrm{AUC}} \mathrm{Ah}_{\mathrm{h}}$ is $52 \%$ of the $\mathrm{AUC}_{\infty}$ for lidocaine and $31 \%$ for mepivacaine. The $\mathrm{AUC}_{3 \mathrm{~h}}$ is required for the calculation of the AUC of the metabolite (MEGX, PPX, 4-OH) because after $3 \mathrm{~h}$ sampling this compound shows a plateau plasma concentration. Elimination must be visible when a much longer sampling period could have been applied. This was impossible by the nature of the type of day case surgery and the allotted time by the hospital rules.

Calculated clearance was based on the assumption of $100 \%$ bioavailability $(\mathrm{F}=1)$. The total body clearances based on $\mathrm{AUC}_{\infty}$ and $\mathrm{AUC}_{3 \mathrm{~h}}$ of lidocaine equaled the maximum average liver blood flow of $1.51 \mathrm{~min}^{-1}\left(90 \mathrm{l} \mathrm{h}^{-1}\right)$, while that of mepivacaine was half that of the liver blood flow.

\section{Comparison of Metabolism}

The metabolism of lidocaine and mepivacaine proceeds via cytochrome P450 isoenzymes, resulting in N-hydroxylation, N-dealkylation (MEGX, GX), and the principal reaction of 4-hydroxylation 
( $80 \%$ of the dose in urine)[27,28,29,30,31,32,33,34,35,36,37,38]. In this study we were able to measure the plasma concentration of MEGX, which increased to $17 \%$ of the lidocaine plasma concentration, and its $\mathrm{AUC}_{\mathrm{t}}$ was $13 \%$ of that of the $\mathrm{AUC}_{\mathrm{t}}$ of parent drug. The plasma concentrations of the mepivacaine metabolites increased to $15.7 \%$ (4-OHmepivacaine) and $20.0 \%$ (PPX) of the concentration of the parent drug. The $\mathrm{AUC}_{\mathrm{t}}$ of the mepivacaine metabolites was $3.89 \%$ (PPX) and $3.24 \%$ (4-OHmepivacaine) of the $\mathrm{AUC}_{\mathrm{t}}$ of mepivacaine. Measurement of the metabolite MEGX was not possible when lidocaine was administered in IVRA at a (low) dose of $200 \mathrm{mg}$ [39].

The enantiomers of $( \pm)$ mepivacaine show the same pharmacokinetic behaviour, which is also similar to the pharmacokinetics of the racemate[7,40], while $\mathrm{D}(-)$-mepivacaine is more active than $\mathrm{L}(+)$-mepivacaine[41,42,43].

\section{CONCLUSION}

It can be concluded that both lidocaine and mepivacaine are suitable and safe agents for axillary brachial plexus block with rapid onset of good surgical analgesia. This is in line with everyday practice in most institutions. Both compounds are absorbed rapidly from the neurovascular sheath and eliminated with a short $\mathrm{t}_{1 / 2 \beta}$ of $2.9 \mathrm{~h}$ for lidocaine and $4.8 \mathrm{~h}$ for mepivacaine.

Mepivacaine is a racemic mixture, which to date is considered to be not theoretically correct, however clinically this racemic mixture is effective and nontoxic in the dose applied. Although there are kinetic differences between the two drugs, they have no clinical consequences.

\section{ACKNOWLEDGEMENT}

This study was funded by the Foundation for Development of Anaesthesiology, Nijmegen, the Netherlands.

\section{REFERENCES}

1. Bier, A. (1908) Über einen neuen Weg Lokalanästhesie an den Gliedmaassen zu erzeugen. Arch. Klin. Chir. 86, 1007-1016.

2. Hirschell, G. (1911) Die anästhessierung des plexus brachialis bei operationen an der oberen extremität. Muench. Med. Wochenschr. 58, 1555-1556.

3. Pearce, H., Lindsay, D., and Leslie, K. (1996) Axillary brachial plexus block in two hundred consecutive patients. Anaesth. Intensive Care 24, 453-458.

4. Winnie, A.P. (1984) Perivascular techniques of brachial plexus block. In Plexus Anesthesia. Vol. 1. Håkannson, L., Ed. Schultz/Churchill Livingstone, New York. pp. 121-144.

5. Aantaa, R., Kirvelä, O., Lahdenperä, A., and Nieminen, S. (1994) Transarterial brachial plexus anesthesia for hand surgery: a retrospective analysis of 346 cases. J. Clin. Anesth. 6, 289-292.

6. Arthur, G.R., Scott, D.H.T., Boyes, R.N., and Scott, D.B. (1979) Pharmacokinetic and clinical pharmacological studies with mepivacaine and prilocaine. Br. J. Anaesth. 51, 481-485.

7. Burm, A.G.L., Cohen, I.M.C., van Kleef, J.W., Vletter, A.A., Olieman, W., and Groen, K. (1997) Pharmacokinetics of the enantiomers of mepivacaine after intravenous administration of the racemate in volunteers. Reg. Anesth. Pain Manage.. 84, 85-89.

8. Büttner, J., Klose, R., and Dreesen, H. (1987) Vergleichende Untersuchung von Prilocain $1 \%$ und Mepivacain $1 \%$ zur axillären Plexusanaesthesie. Reg. Anesth. 10, 70-75.

9. Hollmén, A. (1966) Axillary plexus block. Acta Anaesth. Scand. Suppl XXI, 53-56.

10. Laguarda Rodrigo, M., Sánchez Alcaraz, A., Sangrador García, G., Botello Miro, J., and Herrero Gracia, C. (1990) Farmacocinética de la mepivacaína y de la lidocaína tras su administración epidural. Rev. Esp. Anestesiol. Reanim. 37, 269-272.

11. Moore, R.G., Thomas, J., Triggs, E.J., Thomas, D.B., Burnard, E.D., and Shanks, C.A. (1978) The pharmacokinetics and metabolism of the anilide local anesthetics in neonates. Eur. J. Clin.Pharmacol. 14, 203-212.

12. Schüle, H. (1980) Klinisch-experimentelle Untersuchungen über die Verkehrstüchtigkeit nach zahnärztlichen Eingriffen. D. Zahnärztl. Z. 35, 183-189. 
13. Wörner, H., Frank, S., and Stumpf, H. (1980) Lokalanästhesie und Verkehrstüchtigkeit. D. Zahnärztl. Z. 35, 377384.

14. Vree, T.B., Baars, A.M., van Oss, G.E.C.J.M., and Booij, L.H.D.J. (1988) High performance liquid chromatography and preliminary pharmacokinetics of articaine and 2-carboxy metabolite articainic acid in humans in serum and urine. J. Chromatogr. 424, 440-444.

15. Proost, J.H. and Meijer, D.K.W. (1992) MW/Pharm, an integrated software package for drug dosage regimen calculation and therapeutic drug monitoring. Comput. Biol. Med. 22, 155-163.

16. Borchard, U. and Niesel, H.C. (1994) Grundlagen der Pharmakologie der Lokalanästhetika. In Regionalanästhesie Lokalanästhesie Regionale Schmerztherapie. Niesel H.C., Ed. Georg Thieme Verlag, Stuttgart. pp. 35-68.

17. Niesel, H.C. (1994) Klinische Pharmakologie und Toxikologie. Anwendung der Lokalanästhetika. In Regionalanästhesie Lokalanästhesie Regionale Schmerztherapie. Niesel, H.C., Ed. Georg Thieme Verlag, Stuttgart. pp. 69-165

18. Eriksson, E. (1966) Prilocaine, an experimental study in man of a new local anaesthetic with special regards to efficacy, toxicity and excretion. Acta Chir. Scand. Suppl. 358, 10-24.

19. Goebbel, W.M., Allen, G., and Randall, F. (1980) Comparative circulatory serum levels of $2 \%$ mepivacaine and $2 \%$ lignocaine. Br. Dent. J. 148, 261-264.

20. Hargrove, R.L., Hoyle, J.R., Parker, J.B.R., Beckett, A.H., and Boyes, R.N. (1966) Blood lignocaine levels following intravenous regional analgesia. Anaesthesia 21, 37-41.

21. Merrifield, A.J. and Carter, S.J. (1965) Intravenous regional analgesia: lignocaine blood levels. Anaesthesia 20, 287-303.

22. Sorbie, C. and Chacha, P. (1965) Regional anaesthesia by the intravenous route. Br. Med. J. 1, 957-960.

23. Tucker, G.T., Moore, D.C., Bridenbaugh, P.O., Bridenbaugh, L.D., and Thompson, G.E. (1972) Systemic absorption of mepivacaine in commonly used regional block procedures. Anesthesiology 37, 277-287.

24. Brown, W.U., Bell, G.C., Weiss, J.B., and Alper M.H. (1977) Mepivacaine in amniotic fluid following maternal epidural anesthesia. Anesthesiology 47, 384-386.

25. Deacock, A.R.C. and Simpson, W.T. (1964) Fatal reactions to lignocaine. Anaesthesia 19, $217-221$.

26. Hillman, L.S., Hillman, R.E., and Dodson, W.E. (1979) Diagnosis, treatment, and follow- up of neonatal mepivacaine intoxication secondary to paracervical and pudential blocks during labor. J. Pediatr. 95, 472-477.

27. Boyes, R.N. (1975) A review of the metabolism of amide local anaesthetic agents. Br. J. Anaesth. 47, $225-230$.

28. Couts, R.T., Torok-Both, G.A., Chu, L.V., Tam, Y.K., and Pasutto, F.M. (1987) In vivo metabolism of lidocaine in the rat. Isolation of urinary metabolites as pentafluorobenzoyl derivatives and their identification by combined gas chromatography- mass spectrometry. J. Chromatogr. 421, 267-280.

29. Couts, R.T., Torok-Both, G.A., Tam, Y.K., Chu, L.V., and Pasutto, F.M. (1987) Acetylation and pentafluorobenzoylation of lidocaine metabolites in aqueous solution and identification of derivatives by combined gas chromatography- mass spectrometry. Biomed. Environ. MassSpectrom. 14, 173-182.

30. Hollunger, G. (1960) On the metabolism of lidocaine. The biotransformation of lidocaine. Acta Pharmacol. Toxicol. 17, 365-373.

31. Kammerer, R.C. and Schmitz, D.A. (1986) Lidocaine metabolism by rabbit-liver homogenate and detection of a new metabolite. Xenobiotica 16, 681-690.

32. Meffin, P.J. and Thomas, J. (1973) The relative rates of formation of the phenolic metabolites of mepivacaine in man. Xenobiotica 3, 625-632.

33. Meffin, P., Robertson, A.V., Thomas, J., and Winkler, J. (1973) Neutral metabolites of mepivacaine in humans. Xenobiotica 3, 191-196.

34. Saville, B.A., Gray, M.R., and Tam, Y.L. (1987) Mechanisms of lidocaine in the isolated perfused rat liver. Kinetics of steady state elimination. Drug Metab. Dispos. 15, 17-21.

35. Tam, Y.K., Tawfik, S.R., Ke, J., Coutts, R.T., Gray, M.R., and Wyse, D.G. (1987) High-performance liquid chromatography of lidocaine and nine of its metabolites in human plasma and urine. J. Chromatogr. 423, 199-206.

36. Tam, Y.K., Yau, M., Berzins, R., Montgomery, P.R., and Gray, M. (1987) Mechanisms of lidocaine kinetics in the isolated perfused rat liver. Effects of continuous infusion. Drug Metab. Dispos. 15, 12-16.

37. Tam, Y.K., Ke, J., Coutts, R.T., Wyse, D.G., and Gray, M.R. (1990) Quantification of three lidocaine metabolites and their conjugates. Pharm. Res. 7, 504-507.

38. Tucker, G.T. and Mather, L.E. (1979) Clinical pharmacokinetics of local anaesthetics. Clin. Pharmacokinet. 4, 241-278.

39. Simon, M.A.M., Gielen, M.J.M., Vree, T.B., and Booij, L.H.D.J. (1998) Disposition of lignocaine for intravenous regional anaesthesia during day-case surgery. Eur. J. Anaesth. 15, 32-37.

40. Vree, T.B., Beumer, E.M.C., Lagerwerf, A.J., Simon, M.A.M., and Gielen, M.J.M. (1992) Clinical pharmacokinetics of $\mathrm{R}(+)$ and $\mathrm{S}(-)$-mepivacaine after high doses of racemic mepivacaine with epinephrine in the combined psoas compartment/sciatic nerve block. Anesth. Analg. 75, 75-80. 
41. Åberg, G. and Andersson, R. (1972) Studies on mechanisms of mepivacaine and its optically active isomers on isolated smooth muscle: role of $\mathrm{Ca}^{++}$and cyclic AMP. Acta Pharmacol. Toxicol. 31, 321-336.

42. Adler, R., Adler, G., and Åberg, G. (1969) Effects of optically active isomers and racemate of mepivacaine (Carbocaine) in dental anaesthesia. Sven. Tandlaek. Tidskr. 62, 501-504.

43. Jeske, A.H. and Gangarosa, L.P. (1981) The determination of the vasoactivity of mepivacaine and its isomers. Methods Find. Exp. Clin. Pharmacol. 3, 33-39.

\section{This article should be referenced as follows:}

Simon, M.A.M., Vree, T.B., Gielen, M.J.M., Booij, L.H.D.J., and Lagerwerf, A.J. (2002) Similar motor block effects and disposition kinetics between lidocaine and ( \pm )mepivacaine in patients undergoing axillary brachial plexus block during day case surgery TheScientificWorldJOURNAL 2, 1306-1319.

\section{Handling Editor:}

Alain P. Rolland, Principal Editor for Drug Delivery — a domain of TheScientificWorldJOURNAL. 


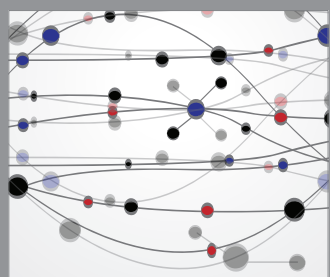

The Scientific World Journal
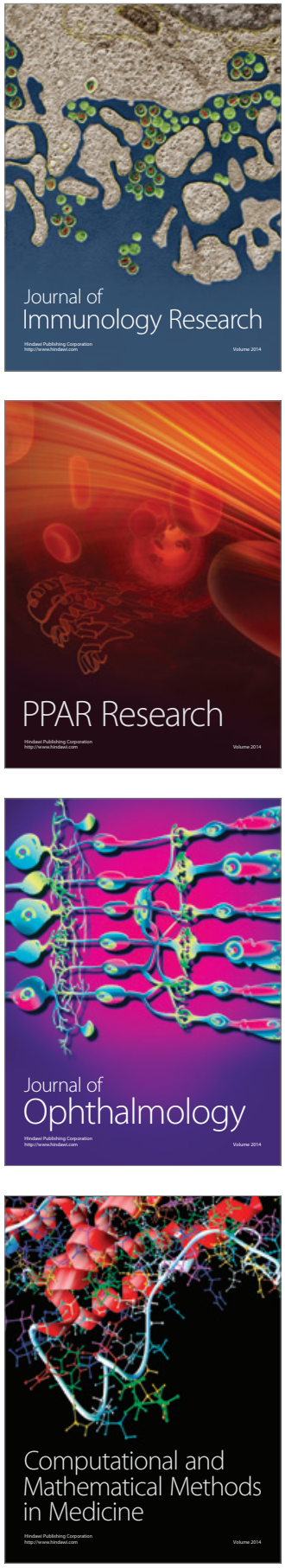

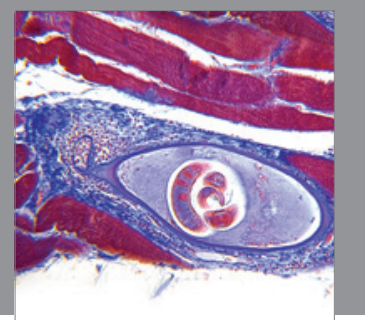

Gastroenterology

Research and Practice
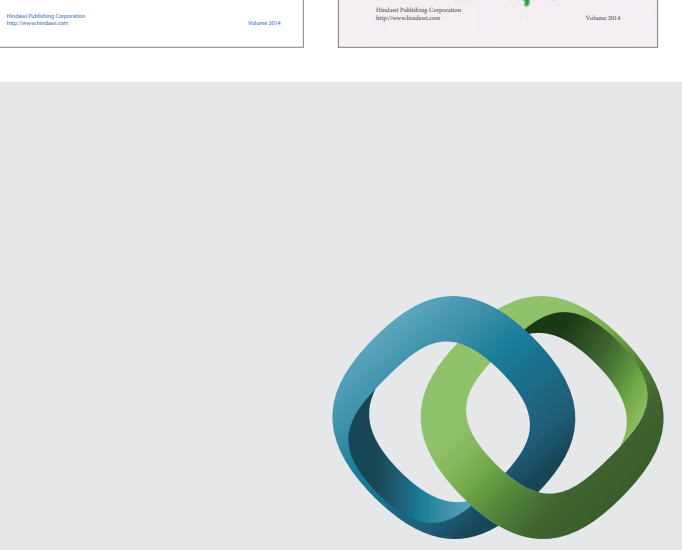

\section{Hindawi}

Submit your manuscripts at

http://www.hindawi.com
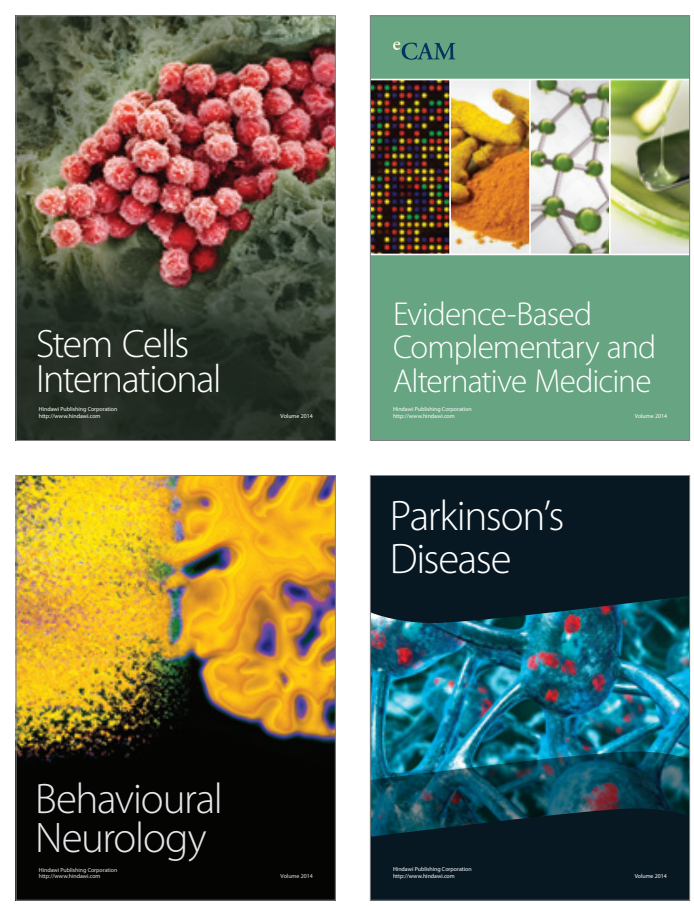

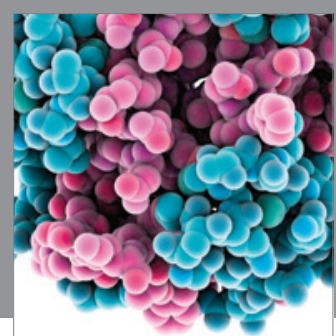

Journal of
Diabetes Research

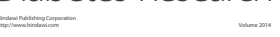

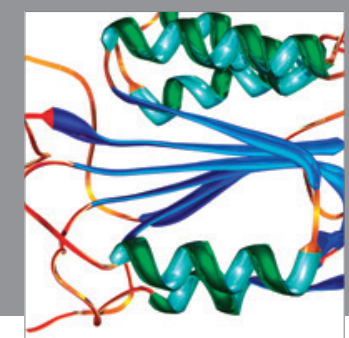

Disease Markers
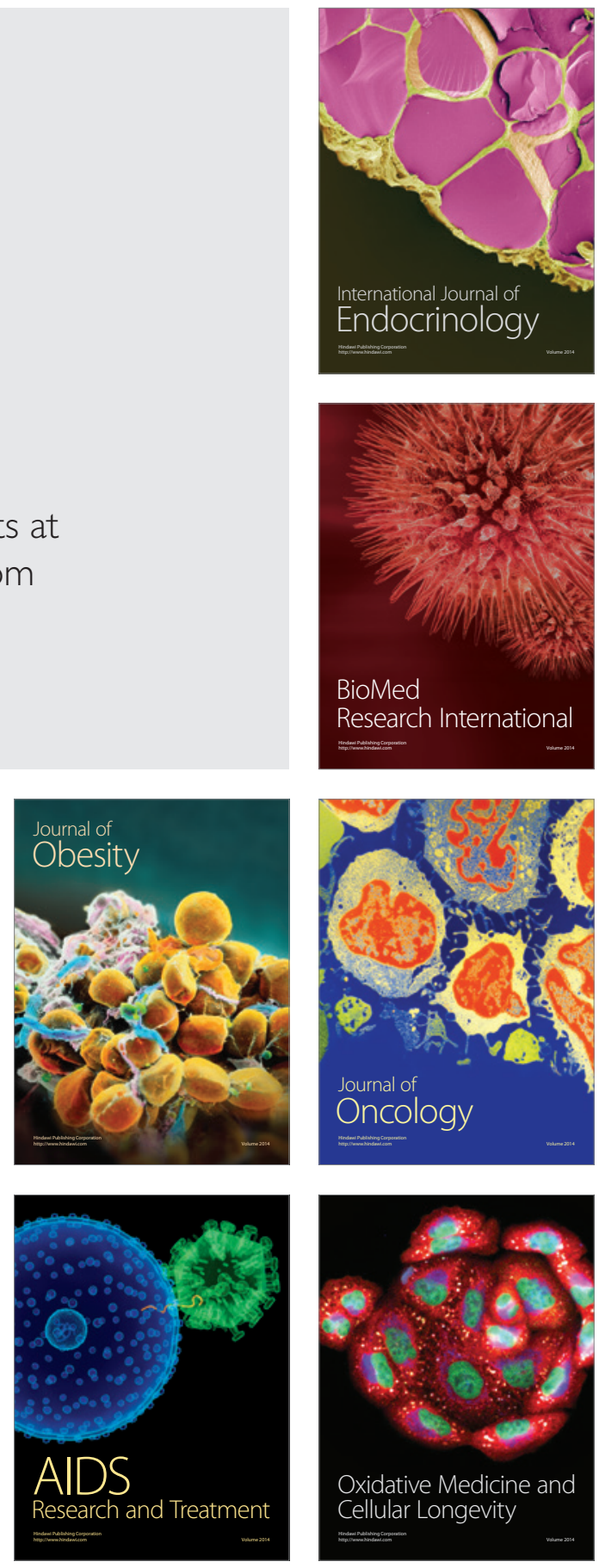